\title{
A Conversation with Yang Dan
}

\author{
INTERVIEWER: REBECCA LESHAN \\ Director, Banbury Center, Cold Spring Harbor Laboratory
}

\begin{abstract}
Yang Dan is the Paul Licht Distinguished Professor of Molecular and Cell Biology at the University of California, Berkeley, a Howard Hughes Medical Institute Investigator, and a member of the U.S. National Academy of Sciences.
\end{abstract}

Rebecca Leshan: I wonder if you could kick us off by giving us a snapshot of your research.

Dr. Dan: I used to work on the visual system until about seven or eight years ago and now about three-quarters of my lab works on sleep and the other quarter works on the prefrontal cortex. So I'm still sort of living two lives.

Rebecca Leshan: Sleep feels like such a basic system, a basic process of humans, and yet there're so many unknowns. Are you finding that there have been new tools in terms of genomics, in terms of optogenetics, that have really pushed the field forward more recently?

Dr. Dan: Absolutely. Both things that you said are crucial for our research program. Optogenetics is crucial. Without it, I probably would never have even moved into sleep. Because that tool was available and I started using it in the visual system, I realized how powerful it is and I see this new opportunity to apply it to sleep research. More recently, we've also been doing a lot of sequencing, gene profiling. Without it being cheap, we would not be able to afford it.

Rebecca Leshan: You work primarily in rodent models systems. Because sleep differs so much between animals, how do you make conclusions or make inferences across species, even to humans, using different models?

Dr. Dan: At the moment, we're mostly focusing on rodents and I always worry about that question: "How much of what we learn can be generalized to humans?" There are immediate differences. The biggest one is rodents are nocturnal, not diurnal, so even for circadian regulation ... there has to be a sign flip somewhere. When light comes on, we're awake, but for rodents, light makes them sleepy. How does that work? I think that if we learn something in the rodent, the generalization to human would be more complicated. But at the moment we're focusing on the basic circuits controlling sleep and those circuits are mostly in the hypothalamus, the brainstem. Those are older circuits. Hopefully, they're better preserved across species, in particular in vertebrates, but that's just the hope.
Rebecca Leshan: I'm glad you brought up the hypothalamus because it strikes me that a lot of the circuits that you describe in your publications on sleep involve a lot of the same pathways that control things like reproduction, circadian rhythms, metabolism. Do you think there's a connection?

Dr. Dan: I think there's got to be a lot of connections. I wasn't thinking like that when we first started working on sleep, but more and more I think so. I think that sleep has a lot to do with metabolism and that's why if you have sleep disturbances, there are a lot of metabolic-related diseases as well. Even in our own research, sometimes we find neurons that we thought are sleep neurons because that's the problem that we study, but then accidentally we find that they're involved in these other things.

For example, a few years ago we found some neurons that really powerfully promoted REM [rapid-eye movement] sleep: the state when we dream. Then we realized that when we activate these neurons when the animals are awake, we don't push them to sleep. Part of that is because normally we have to go from wakefulness to non-REM sleep and then go into REM sleep. So you don't have the direct transition from wake to REM, which is part of the reason why when we activate them during wakefulness, they don't go to REM sleep. But then we said, "Okay, we don't get them to go into REM sleep. So what happens?" We realized that actually we slightly enhanced their eating. So that got me thinking that a lot of these things are so fundamental to our survival and they're all related somehow.

Rebecca Leshan: If you can't sleep, why not eat? Were these the preoptic-area neurons?

Dr. Dan: No. The REM circuits tend to be more in the brainstem. Those are the neurons that we found in this region called the medulla. They're very posterior, right above the spinal cord.

Rebecca Leshan: How does your work and the study of sleep relate to things like coma or anesthesia or other differences in arousal?

(C) 2018 Dan. This article is distributed under the terms of the Creative Commons Attribution-NonCommercial License, which permits reuse and redistribution, except for commercial purposes, provided that the original author and source are credited. 
Dr. Dan: I haven't studied that myself because I still have a relatively short history in sleep, but I know they're quite different. One definition of sleep is that you're passed out but it's easily reversible, whereas coma is not easily reversible, so there's a difference right there. It depends on the types of coma. In some cases, the EEG [electroencephalogram] — which is a measure of population activitycould just go flat, but during sleep our brain is actually very active. You can measure these large-amplitude slow waves that propagate across big parts of the brain. So that could be quite different from many types of coma.

Rebecca Leshan: Coma would be more similar to an anesthetized state?

Dr. Dan: Anesthesia's also complicated, depending on what anesthetics you're using. My understanding is that under anesthesia if you measure the brain activity EEG, it looks very different from the sleep EEG, but there are certain anesthetic drugs that make it look more like the sleep state.

Rebecca Leshan: We know that sleeping patterns change with age, from an infant all the way up to an elderly adult. Are you studying more of that central adult brain or are you looking across how things change in the life span?

Dr. Dan: So far we've been focusing on just the standard young adults' kind of sleep, but it would definitely be very interesting to look at how aging affects it, and how development affects it. So, both ends of the life span.

Rebecca Leshan: What do you think has been the biggest breakthrough in this field? Maybe it's optogenetics that's really changed the way that you can do research or maybe it's access to data, maybe it's people's interest in an area?

Dr. Dan: Obviously, I'm biased. There are a lot of interesting new techniques for human sleep studies as well, like the wearable devices that can measure human sleep, but I'm focusing on rodent sleep. In terms of those techniques, for me personally, optogenetics is definitely very important. Chemogenetics, as well. The point is that now you can target particular genetically defined cell types. The key word is "genetics," because if you have a Cre line labeling a cell type that has a particular marker, you can really just target those cell types very specifically, even if they're spatially intermingled with a whole bunch of other cell types. Whereas in the old days - pharmacology or electrical stimulation-you're activating the whole population. Related to that, if you want to figure out what cell type you want to target, then sequencing is also very important. My lab actually got into sequencing pretty recently and that's because the techniques have become so affordable and also relatively easy to do.

Rebecca Leshan: Would you tie the genomics in with some of the brain mapping projects that are currently underway?

Dr. Dan: There are several big projects going on trying to figure out all the cell types, the atlas in terms of cell types. Those are fantastic, because for individual small labs it's very hard to do that on a large scale. Usually we have a particular narrow question, so we count pennies and say "Oh, we can afford to do this one thing," but if somebody can actually make a coherent effort to just put the data out there, it's incredibly useful for people like us. For example, the Allen Institute connectivity data set. Every day in my office, I have their data set open in multiple windows. I can click different windows and just check out the data.

Rebecca Leshan: Is there something that's been a big hurdle, either technological or just a lack of funding, that's really held back research in the area?

Dr. Dan: I think sleep in general hasn't been sufficiently supported, but I'll bet everybody thinks that they're insufficiently supported. I do feel that sleep, in particular, is so important because we spend a third of our lifetime doing that.

Rebecca Leshan: You can envision that, in the future, being able to quickly put yourself into sleep and then get yourself out of it would be the ideal situation.

Dr. Dan: That's certainly what we hope to do. Especially with optogenetics, you can almost do that to the mouse. If you find sleep neurons, that's what we do every day. We try to find the neurons where we turn on the light and within ten seconds they fall asleep. That will be pretty cool. But that's still optogenetics. You've got to inject a virus into the brain; you've got to implant the optic fibers.

Rebecca Leshan: How far away do you think we are from having actual clinical interventions?

Dr. Dan: In the last seven-and-a-half years, we've been mostly just focusing on the basic circuit, but recently I've been thinking more and more about application. I'm thinking about two general approaches. One is to develop better sleeping pills. Psychologically, to do anything else, to open a hole in the head is scary, but we've been taking pills forever. But the current sleeping pills, they're not perfect. For example, Ambien. I think that part of the problem is it's targeting too broad of a system-the GABAergic system: which part of the brain doesn't use GABA $[\gamma$-aminobutyric acid $]$ ?

My lab has a big focus of finding the particular markers for the sleep neurons. Once we find a marker, we actually do recordings on single cells to make sure it's a relatively homogeneous population for sleep. Once you do that, you can ask what are the genes that are specifically expressed in this population of neurons, not just in this brain region. The hypothalamus is very heterogeneous, but if you know the cell type and you've done the physiology to know that it's homogeneous, then that gives you a better chance. Then if we can sequence them, see what genes are highly enriched in the cells, then maybe some of them are druggable and then you can go through the whole process of screening for molecules and develop drugs.

Rebecca Leshan: We've talked a little bit about some of these overlapping functions in the same brain region, even overlapping peptides. I think of something like galanin, which is implicated in so many different processes. Pre- 
sumably, you wouldn't want to target that. Do you think we will be able to find something that's doing a single function?

Dr. Dan: That's a big unknown. We've been using a lot of peptide markers and they're excellent markers. In fact, we got pretty lucky just to bet on the peptides as markers and it turns out it works quite well. On the other hand, it's also true that each peptide is probably involved in multiple things because they're not just expressed in the neurons you're interested in; they're in other brain regions as well. I'm not sure if they're necessarily good targets for drugs, but then our hope is to also look at other things like GPCRs [G-protein-coupled receptors]. They may not be the best markers for targeting the cells in our basic research, but they're probably very good drug targets. But you never know, because you could sequence the whole thing and maybe you realize that none of the druggable ones are specific enough. At least it's something that we like to try.

Rebecca Leshan: It seems like there are so many out there right now with unknown function. It's a bigger pool to draw from.

Dr. Dan: Exactly. That's one direction I'm thinking about. The other thing is actually related to the work from [Antonello] Bonci. He thought that going from optogenetics with a cell-type specificity to direct stimulation was never going to work. But in fact it worked remarkably well. It's something that I'm thinking about, too. You know you're going to lose the cell-type specificity, but who knows? Maybe it'll just work, like deep brain stimulation. It's working better than most of us would have thought.
Rebecca Leshan: You've mentioned that you are new to the sleep field and I know you originally studied physics. This is such an interdisciplinary space and becoming even more so. Have you found that that's been an advantage to you? Do you find that you train your students and postdocs differently to be a little bit more open to different disciplines? Where do you see training in this space changing as it becomes more broad?

Dr. Dan: My personal experience is that being trained in a different field, you could really turn that into an advantage. It's not like training in one is better than the other, but I feel that being a little different from a lot of your peers studying the same problem is an advantage because you just think a little differently. If you all think the same way, then it's a matter of who gets there first. But if you think a little differently, you have a slightly different angle. I think that's interesting. Of course, there are also challenges. I remember my first year in graduate school I was just struggling trying to keep up with the courses because everything's so new, but I think that once you get over that phase, then you start seeing some advantages.

Rebecca Leshan: And maybe feel empowered to learn even more new things.

Dr. Dan: That's the other thing. Because I've done that, switching from physics to biology. The first year was hell, but then after that, I felt pretty good about it. And once you've done that once, you become more brave. You feel like if you can do it once, you can do it again. So switching to the sleep field is something that I thought, it's not going to be easy, because I remember my early days. But I thought that, if you just work hard, if you can get through that initial barrier, maybe it'll work. 


\section{$\$_{\text {CSH\& }}^{\infty}$ Cold Spring Harbor Symposia SYMPOSIA On Quantitative Biology}

\section{A Conversation with Yang Dan}

Cold Spring Harb Symp Quant Biol 2018 83: 243-245 originally published online May 16, 2019 Access the most recent version at doi:10.1101/sqb.2018.83.037564

Creative This article is distributed under the terms of the

Commons http://creativecommons.org/licenses/by-nc/4.0/, which permits reuse and

License redistribution, except for commercial purposes, provided that the original author and source are credited.

Email Alerting Receive free email alerts when new articles cite this article - sign up in Service the box at the top right corner of the article or click here. 